Article

\title{
Economic Dispatch of Multi-Energy System Considering Load Replaceability
}

\author{
Tao Zheng ${ }^{1,2,3, *}$, Zemei Dai ${ }^{1,2,3}$, Jiahao Yao ${ }^{4}$, Yufeng Yang ${ }^{1,2,3}$ and Jing Cao ${ }^{1,2,3}$ \\ 1 NARI Group Corporation (State Grid Electric Power Research Institute), Nanjing 211106, China \\ 2 NARI Technology Development Co. Ltd., Nanjing 211106, China \\ 3 State Key Laboratory of Smart Grid Protection and Control, Nanjing 211106, China \\ 4 Key Laboratory of Measurement and Control of Complex Systems of Engineering, Ministry of Education, \\ School of Automation, Southeast University, Nanjing 210096, China \\ * Correspondence: zhengtao2@sgepri.sgcc.com.cn
}

Received: 28 July 2019; Accepted: 23 August 2019; Published: 28 August 2019

check for updates

\begin{abstract}
By integrating gas, electricity, and cooling and heat networks, multi-energy system (MES) breaks the bondage of isolated planning and operation of independent energy systems. Appropriate scheduling of MES is critical to the operational economy, and it is essential to design scheduling strategies to achieve maximum economic benefits. In addition to the emergence of energy conversion systems, the other main novelty of MES is the multivariate of load, which offers a great optimization potential by changing load replaceability (flexibly adjusting the composition of loads). In this paper, by designing load replaceability index (LRI) of composite load in MES, its interaction mechanism with scheduling optimum is systematically analyzed. Through case studies, it is proven that the optimum can be improved by elevating load replaceability.
\end{abstract}

Keywords: multi-energy system; economic dispatch; load replaceability; multi-energy conversion

\section{Introduction}

Energy flexibility is crucial to the construction of more environmental-friendly and efficient power generation (consumption) patterns. Unlike conventional single-form energy-based energy system, which is usually detached from other types of energy systems from both the planning and operational perspectives, multi-energy system (MES) comprises various forms of subsystems including electricity, heat, cooling and gas networks, contributing to the interactions and corresponding energy flexibility through energy converters. Therefore, MES technologies gradually become irreplaceably key components in building the modern energy systems.

Compared with single-from energy-based system, the most significant difference of MES is the energy conversion function achieved by energy conversion equipments, which serve as in-between interfaces and assist in the formation of coupling relations. Energy converters are foundations of transformation, fusion and decomposition of energy flows among different subsystems. Because of the possibility of convertibility of different energy forms, MES outperforms systems of pure energy form by complementing the advantages of each subsystem.

An important concept in MES is the energy hub (EH), which gives an matrix model of production, conversion, consumption and storage of different energy carriers. Each of the matrix elements represent the abstract connection and conversion coefficients of internal components, which can be embodied by various types of multi-generators, among which combined heat and power (CHP) or combined heat cooling and power $(\mathrm{CHCP})$ plants are the most widely investigated cogeneration or trigeneration plants. 
Various research studies have recently begun to show intensive concern for the design and operation of MES, either from the perspective of microscopic (CHP and CHCP plants) or macroscopic (EHs). The main idea of optimal operation of CHP (CHCP) plants is similar to that of power systems, both starts from the optimization model building and ends with model solving by specific optimization algorithms like mathematical or evolutionary programming methods. Like economic electrical power dispatch, the first priority of multi-generation is economy. Some researchers leverage the strong computing capabilities of meta-heuristics to solve economic dispatch of CHP plants [1,2]. Apart from deterministic optimization, uncertainties stemming from volatile renewable energy are gradually introduced by stochastic programming. For example, a novel chance constrained programming model is used to formulate economic dispatch with CHP plants and wind power simultaneously [3]. Li groundbreakingly investigates how to use the temperature dynamics of heating networks to enhance the utilization of wind power, and a CHP dispatch model considering operational economy and wind power integration is built and solved by iterative methods [4]. As for economic dispatch of CHCP, a nonlinear economic optimal operation model is developed and solved by lingo solver [5]. Backward dynamic programming technique is used to obtain the optimal operational set-points of combined heat, cooling and power systems [6].

Besides designing operation schedules solely in pursuit of the economic potential elevation, optimization of (CHP) CCHP plants considering multiple operational output performance begins to capture researchers' interests. Under most circumstances, economy, energy utilization efficiency and environmental preservation are the three main optimization goals. By employing Weighting method and fuzzy optimum selection theory, the integrated performances of operation of CCHP plants considering these objectives are evaluated [7]. Dynamic object method-particle swarm optimization method is used to achieve the goal of carbon emission reduction, energy efficiency elevation and system cost minimization [8]. Additionally, some new evaluation indices evaluating the average useful output and total heat transfer area are studied, correspondingly, a multi-objective optimization-based schedule is designed [9]. Modified Bacterial Foraging Optimization method is adopted to minimize the operational cost and pollutant emission [10].

Optimal system-level operation of MES is usually implemented under EH framework by designing the synergies among generation, consumption and storage components. An optimal operation strategy of MES containing CHP plants, boiler, battery and water tank is studied [11], and particle swarm optimization (PSO) algorithm is used to obtain optimal scheduling of each device. An optimal expansion planning of EH containing CHP plants and natural gas furnaces is designed to minimize investment cost [12]. Under some circumstances MES have some uncertainties involving demand fluctuation, cost dynamics and converter efficiency change. In this situation deterministic framework no longer adapts to uncertain environments, hence robust optimization approach is used to increase the robustness towards uncertain bounded parameters [13]. In [14], uncertainties of demand, market price and renewable energy are considered by stochastic programming, and optimal operation set-points are obtained to minimize operation costs. Instead of treating EH as an individual system, studies of multi-EH systems take into consideration the mutual influence and restriction. By analyzing competitive and cooperative relation between multi-EHs, game theoretic optimal scheduling is established through quantum particle swarm optimization method [15]. Moreover, resilience of MES is researched in last several years, and coordination between different subsystems in post-disaster repair is investigated to reduce load shedding and repair duration [16].

Most of the existing MES research focuses on optimal planning or operation by considering multi-energy generation or conversion on the generation side. Recently, some research studies begin to consider the characteristics of multi-energy loads, which play essential roles in MES planning \& operation as well as other applications like load prediction and demand response programs. Some researchers investigate the influence of multi-energy loads upon MES planning, and the capacity of gas turbine under different thermoelectric ratios is studied [17]. In respect to load prediction, load prediction for integrated cooling and heat system is implemented by considering the intrinsic 
coupling among multi-energy loads using multivariate phase space reconstruction technique [18]. By considering the operating attributes of loads, a quick cooling and heating load prediction model is constructed [19]. Deep-learning technique is adopted to predict various types of load in regional energy system integration [20]. Some researchers also study how to adjust the consumption pattern to better participate in the demand response program [21,22].

Conventionally, the load composition from each energy network is assumed to be fixed without replaceability, which is characterized by the feasibility of substitution of one form of load with another one. Load considering replaceability can be regarded as a composite load, it characterizes the multi-energy consumption on the load side and is essential to flexible and efficient energy consumption. Composite load can adjust the proportion of heterogeneous energy consumption based on the external excitation signal such as market price, thus achieving simultaneous operation cost reduction and the load and generation balance.

In this paper, an optimal scheduling approach for MES consisting of gas, electricity, cooling and heat networks considering load replaceability is designed to maximize the economic potential of operation. For the convenience of analysis of the influence of load replaceability on the optimal scheduling, load replaceability index (LRI), which measures the overall load replaceability of MES, is analyzed in respect to the optimal scheduling results. The intrinsic relations between load replacement capability and optimum under various operating conditions are investigated to improve the scheduling performance by observing specific rules of load replaceability adjustment.

The remaining of the paper is organized as follows: Section 2 addresses load replaceability and the definition of LRI in MES; with the aid of load replaceability, Section 3 presents the economic scheduling model for an integrated electricity, gas, heat and cooling networks; Section 4 studies the relation between optimal scheduling results and load replacement capability; concluding remarks are given in Section 5.

\section{Load Replaceability in Multi-Energy System}

In this section, load replaceability and its relation with optimal scheduling of MES are systematically analyzed. The definition and calculation method of LRI are presented.

\subsection{Load Replaceability and Composite Load}

Load replaceability is used to characterize the selection margin of multi-energy consumption. If one specific load can choose two or more than two types of energy flow to meet its own load demand, and then this load is called replaceable load. From the perspective of consumers, the greater the number of energy flow types is and the greater the capacity of multi-generators is, the more the selection margin of multi-energy consumption is.

Generally speaking, loads in MES can be categorized as cooling, heat, power and gas load, corresponding to their respective type of energy network. Usually, due to the natural barrier between heterogenous energy systems in the isolated operating mode, the load can only be supplied by homogenous energy flow. Nevertheless, with the coupling and integration of heterogenous systems assisted by energy conversion systems, it should be emphasized that the load can be satisfied by heterogenous energy flow as well.

In this section, heat load is taken as an example to illustrate the replaceability phenomenon. In independent heat network, heat load can only be supported by the heat flow through steam pipelines. While heat load in MES can be supplied by various forms of energy. For example, on the one hand heat energy can still be transmitted through pipelines just like in independent heat network; on the other hand electric furnaces or gas heaters can transform electric or gas into heat energy. In this case, in addition to the thermal attribute, heat load has electric attribute (electric heater) and gaseous attribute (gas furnace). Electricity and gas are just intermediate transition states. Seen from the exterior, the final state is still heat load since heat flow is the only energy form in the consumption phase. 
Though the final load state belongs to heat load in either segregated independent system or integrated dependent system, the introduction of intermediate transition states makes the load property change from monotype load in independent system into composite load in dependent system. The main specialty of composite load is flexibility, especially the market response flexibility. The operator can adjust the proportion of each component in the composite load, based on the market price of each form of energy flow at different operating interval, thus reducing operation cost. The emergence of composite load enhances the optimization space in the consumption phase and further increases economic benefits. In order to vividly illustrate how load replaceability (composite load) influences the operation economy, an exemplary integrated gas power and cooling system in Figure 1 is briefly studied.

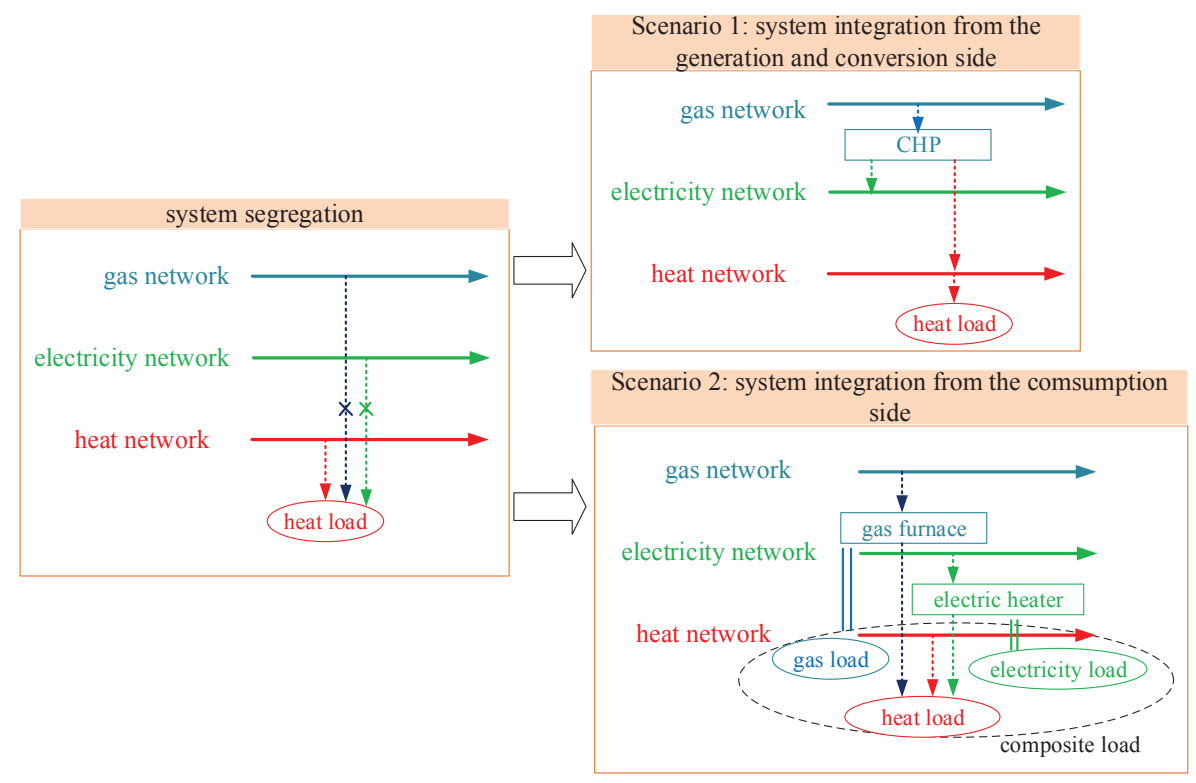

Figure 1. Schematic diagram of two-area classic system.

Suppose the current market prices of gas electricity and heat are $6 \$ / \mathrm{kWh}, 1 \$ / \mathrm{kWh}$ and $15 \$ / \mathrm{kWh}$, respectively. And the amount of heat load demand $(100 \mathrm{kWh})$ is much more than that of electricity or gas load demand, which is set by zero for simplicity. The maximal transmission capacity of each network is $50 \mathrm{~kW}$. The following two scenarios are considered for operation cost calculation.

- Scenario 1: There exists no replaceable heat load in the system; the multi-generation plant is the CHP plant. The overall energy conversion ratio is 0.8 ; the energy proportion of electricity generated by the CHP plant is 0.6 ; the energy proportion of heat generated by the CHP plant is 0.4 . And the maximal capacity of the CHP plant is supposedly to be much bigger than the maximal transmission capacity of the network.

- Scenario 2: There exists replaceable heat load in the system, and the load is composite load which contains electric heater and gas furnace. The maximal capacity of both devices is supposedly to be much bigger than the maximal transmission capacity of power and gas network. The energy efficiency ratio for both devices is 0.5 .

In Scenario 1, the operation cost is

$$
6 \times 50 \times 0.8 \times 0.4+15 \times(100-50 \times 0.8 \times 0.4)=1356 .
$$

In Scenario 2, the operation cost is

$$
1 \times 50 \times 0.5+6 \times 50 \times 0.5+15 \times(100-50)=925 .
$$


As can be seen, due to the load replaceability, consumers can satisfy the demand by consuming much cheaper transformed energy. In this case it is the transformed heat flow from electric heaters and gas furnaces, thus reducing the overall operation cost. Nevertheless, the multi-generation plant (the CHP plant) can only supplement heat flow to a very limited degree. Heat flow is just a byproduct during the intermediate generation section and the multi-generation plant is not ultimately consumption-oriented, which cannot sufficiently use the price difference between different energy forms to reduce operation cost. As is shown by the results in (1) and (2), operation cost (925\$) considering load replaceability is obviously smaller than that is only with multi-generation plants.

\subsection{Load Replaceability Index}

In Section 2.1, basic information of load replaceability and composite load is addressed. From the deduction of a simple 2-scenario integrated energy system, it can be learned that load replaceability enhances the optimization space from the consumption side. In this section, instead of focusing on substitutes of one specific type of load, we give some quantitative indices to evaluate the broad system-level load replaceability. The LRI can reflect to what extent one type of load (the final load state) can be substituted by the other (the intermediate load state).

LRI can be defined from two perspectives: (1) the potential load replaceability and (2) the actual load replaceability. The former evaluates the potential of load substitution of the system before it is ever put into operation. The latter evaluates the actual load substitution ability during the operation.

\subsubsection{Load Replaceability Index Reflecting Potential Load Substitution Ability}

As for an integrated gas, power, heat and cooling system, there exist four possible types of load in the system. Denote the maximal convertible load demand of the $i$ th composite load by $L_{i}^{\max }$, and denote the load component for the $i$ th load from each network by $X_{i}^{\text {load }}, P_{i}^{\text {load }}$ and $G_{i}^{\text {load }} . X_{i}^{\text {load }}$ can either be $C_{i}^{\text {load }}$ or $H_{i}^{\text {load }}$ based on the final energy form. LRI of the $i$ th load can be calculated by

$$
\alpha_{i}=\frac{\left(x_{i} X_{i}^{\text {load }}+u_{i 1} p_{i} P_{i}^{\text {load }}+u_{i 2} g_{i} G_{i}^{\text {load }}-L_{i}^{\max }\right)}{L_{i}^{\max }},
$$

where $x_{i}, p_{i}$, and $g_{i}$ represents the energy efficiency ratio of respective intermediate load. Binary variables $u_{i 1}, u_{i 2} \in\{0,1\}$ represent $i$ th load is $\left(u_{i 1}, u_{i 2}=1\right)$ or is not $\left(u_{i 1}, u_{i 2}=0\right)$ supplied by specific intermediate loads ( $P_{i}^{\text {load }}$ or $G_{i}^{\text {load }}$ ). Suppose there exist $m$ loads in the integrated energy system, the overall LRI can be expressed as

$$
\alpha=\frac{\sum_{i=1}^{m} \alpha_{i} L_{i}^{\max }}{\sum_{i=1}^{m} L_{i}^{\max }}
$$

LRI in (4) actually uses the proportion of remaining alternative load reserve in the maximal load demand to quantify the substitution potential.

\subsubsection{Load Replaceability Index Reflecting Actual Load Substitution Ability}

As can be seen from (4), all the parameters are actually the upper bounds of corresponding replaceable loads. That is to say, (4) reflects the remaining load conversion reserve at critical states (the maximum values). Nevertheless, replaceable loads in the actual scheduling would not certainly be equal to the maximum; values of replaceable loads should depend on the scheduling, which will be presented in detail in the next section. Therefore, a modified online scheduling-based LRI of the $i$ th load is expressed by

$$
\beta_{i}=\frac{u_{i 1} p_{i} P_{i}^{\text {load }}+u_{i 2} g_{i} G_{i}^{\text {load }}}{L_{i}}
$$


where $P_{i}^{\text {load }}$ and $G_{i}^{\text {load }}$ represent the actual intermediate load amount in the scheduling; $L_{i}$ represents the actual composite load demand. Then the system-level LRI can be expressed by

$$
\beta=\frac{\sum_{i=1}^{m} \beta_{i} L_{i}}{\sum_{i=1}^{m} L_{i}} .
$$

Notice that the replaceable load term $x_{i} X_{i}^{\text {load }}$ disappears in (5); it is because that $x_{i} X_{i}^{\text {load }}+u_{i 1} p_{i} P_{i}^{\text {load }}+u_{i 2} g_{i} G_{i}^{\text {load }}=L_{i}$ in the scheduling. If (3) is still used, LRI is always zero. In this case only the proportion of energy converted by intermediate loads in the composite load is used to quantify the degree of flexibility.

\section{Optimal Economic Scheduling of Multi-Energy System Considering Load Replaceability}

It can be learned from Section 2 that load replaceability offers redundant energy flow path and the optimization space of multi-energy complementary coordination. In response to the market price of different energy flow, the consumption side can participate in economic dispatch by adaptively adjusting the proportion of the intermediate load of various energy form in the composite load. Unlike conventional demand response program in power systems, because of the load replaceability capability through conversion systems, this multi-energy demand response in MES does not cause the change in the ultimate total energy consumption. The consumers only choose the intermediate energy source from which they buy to obtain the ultimate energy rather than change the consumption pattern like they do in electric utility demand response programs. That is to say, operation economy along with customer satisfaction on energy supply is guaranteed.

In this section, by considering load replaceability the economic dispatch model is established for MES in Figure 2 consisting of gas, power, and cooling and heat networks.

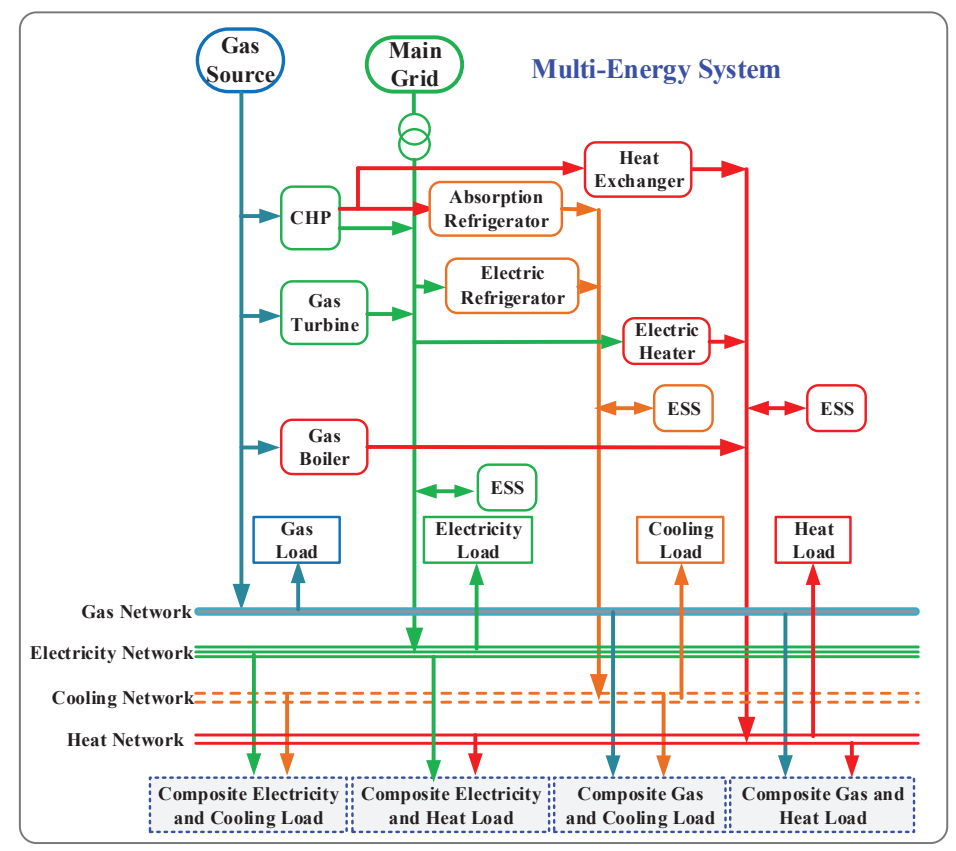

Figure 2. Schematic diagram of a multi-energy system (MES) consisting of gas, power, and cooling and heat networks. $\mathrm{CHP}=$ combined heat and power; ESS = energy storage system. 


\subsection{Objective Function of Optimal Economic Scheduling of MES}

From the perspective of economy, operation cost mainly comes from three aspects including the cost of purchasing gas from external gas networks, the cost of purchasing electricity from external electric grids and depreciation expense of the multi-energy storage systems.

The cost of gas purchase $O_{G}$ is written by the accumulative product of gas price and purchase amount (which is procured from the external gas source shown in Figure 2) during the whole dispatching intervals

$$
O_{G}=\sum_{t=1}^{T} r_{\text {gas }}(t) \frac{G_{\text {ext }}(t)}{R_{\text {gas }}} t
$$

where $t$ represents the dispatch interval; $T$ represents the total number of dispatch intervals; $r_{g a s}(t)$ represents gas price at time $t ; G_{\text {ext }}(t)$ represents gas purchase amount at time $t ; R_{\text {gas }}=9.77\left(\mathrm{kw} \cdot \mathrm{h} / \mathrm{m}^{3}\right)$ represents the calorific value.

The supplementary electricity is procured from the external main grid as shown in Figure 2. Similarly, we can compute the cost of electricity purchase $O_{P}$ as

$$
O_{P}=\sum_{t=1}^{T} r_{e l e}(t) P_{e x t}(t) t
$$

where $t$ and $T$ have the same meaning as in $(7) ; r_{\text {ele }}(t)$ represents electricity price at time $t$; and $P_{\text {ext }}(t)$ represents electricity purchase amount at time $t$.

The depreciation cost steams from ageing of storage system during the repeated energy charge/discharge processes. In this paper, it is assumed that gas is either directly supplied to gas load or converted to other energy flow, and there is no gas storage system. For simplicity, it is expressed as the linear combination of storage amount of different energy flow:

$$
O_{S}=\sum_{t=1}^{T}\left[r_{P S} P_{P S}^{S}(t)+r_{H S} H_{H S}^{S}(t)+r_{C S} C_{C S}^{S}(t)\right]
$$

where $r_{P S}, r_{H S}$, and $r_{C S}$ represent the depreciation rate per unit quantity of power, and heat and cooling energy; $P_{P S}^{S}(t), H_{H S}^{S}(t)$ and $C_{C S}^{S}(t)$ represent the electricity, and heat and cooling energy stored at time $t$.

\subsection{Constraints of Optimal Economic Scheduling of MES}

\subsubsection{Energy Supply and Demand Balance}

Similar to power balance equation in electric grids, the energy supply and demand balance should be guaranteed at the first place. Nevertheless, due to the coupling enabled by conversion systems, the energy generation side might contain transformed energy flow (the output of conversion systems), the energy consumption side might contain energy flow to be transformed (the input of conversion systems), which is exactly the intermediate load previously addressed in Section 2. Therefore, under the circumstances of MES, the load for each network can be categorized by convertible load and inconvertible load, which are equivalent to intermediate and ultimate load in Section 2.

The energy supply and demand balance equation for the cooling system can be written by

$$
C_{A R}(t)+C_{E R}(t)+C_{C S}^{R}(t)-C_{C S}^{S}(t)=C_{\text {load }}^{D}(t)+C_{\text {load }}^{P C}(t)+C_{\text {load }}^{G C}(t),
$$

where $t$ represents the dispatch interval; $C_{A R}(t)$ represents cooling energy generated by the absorption refrigerator; $C_{E R}(t)$ represents cooling energy generated by the electric refrigerator; $C_{C S}^{R}(t)$ represents cooling energy released by cooling energy storage system; $C_{C S}^{S}(t)$ represents cooling energy 
stored by cooling energy storage system; $C_{\text {load }}^{D}(t)$ represents inconvertible cooling load; $C_{\text {load }}^{P C}(t)$ represents convertible electricity-based cooling load; and $C_{\text {load }}^{G C}(t)$ represents convertible gas-based cooling load.

Similarly, the energy supply and demand balance equation for the heat system can be written by

$$
H_{H E}(t)+H_{G B}(t)+H_{E H}(t)+H_{H S}^{R}(t)-H_{H S}^{S}(t)=H_{\text {load }}^{D}(t)+H_{\text {load }}^{P H}(t)+H_{\text {load }}^{G H}(t),
$$

where $H_{H E}(t)$ represents heat energy generated by heat exchanger; $H_{G B}(t)$ represents heat energy generated by gas boiler; $H_{E H}(t)$ represents heat energy generated by electric heater; $H_{H S}^{R}(t)$ represents heat energy released by heat energy storage system; $H_{H S}^{S}(t)$ represents heat energy stored by heat energy storage system; $H_{\text {load }}^{D}(t)$ represents inconvertible heat load; $H_{\text {load }}^{P H}(t)$ represents convertible power-based heat load; and $H_{\text {load }}^{G H}(t)$ represents convertible gas-based heat load.

The energy supply and demand balance equation for the gas system can be written by

$$
G_{\text {ext }}(t)-G_{C H P}(t)-G_{G T}(t)-G_{G B}(t)=G_{\text {load }}^{D}(t)+G_{\text {load }}^{G C}(t)+G_{\text {load }}^{G H}(t),
$$

where $G_{C H P}(t)$ represents gas energy consumed by the CHP plant; $G_{G T}(t)$ represents gas energy consumed by the gas turbine; $G_{G B}(t)$ represents gas energy consumed by the gas boiler; $G_{\text {load }}^{D}(t)$ represents inconvertible gas load; $G_{\text {load }}^{G C}(t)$ represents convertible cooling-oriented gas load; and $G_{\text {load }}^{G H}(t)$ represents convertible heat-oriented gas load.

The energy supply and demand balance equation for the power system can be written by

$$
P_{\text {ext }}(t)+P_{C H P}(t)+P_{G T}(t)+P_{P S}^{R}(t)-P_{P S}^{S}(t)-P_{E H}(t)-P_{E R}(t)=P_{\text {load }}^{D}(t)+P_{\text {load }}^{P C}(t)+P_{\text {load }}^{P H}(t),
$$

where $P_{C H P}(t)$ represents electricity energy generated by the CHP plant; $P_{G T}(t)$ represents electricity energy generated by the gas turbine; $P_{P S}^{R}(t)$ represents electricity energy released by the electricity energy storage system; $P_{P S}^{S}(t)$ represents electricity energy stored by the electricity energy storage system; $P_{E H}(t)$ represents electricity energy consumed by the electric heater; $P_{E R}(t)$ represents electricity energy consumed by the electric refrigerator; $P_{\text {load }}^{D}(t)$ represents inconvertible power load; $P_{\text {load }}^{P C}(t)$ represents convertible cooling-oriented power load; and $P_{\text {load }}^{P H}(t)$ represents convertible heat-oriented power load.

As can be seen from (10)-(13), there exist inconvertible load $C_{\text {load }}^{D}(t), H_{\text {load }}^{D}(t), G_{\text {load }}^{D}(t)$, and $P_{\text {load }}^{D}(t)$; meanwhile, the convertible load during the intermediate transition state are $C_{\text {load }}^{P C}(t), C_{\text {load }}^{G C}(t)$, $H_{\text {load }}^{P H}(t), H_{\text {load }}^{G H}(t), G_{\text {load }}^{G C}(t), G_{\text {load }}^{G H}(t), P_{\text {load }}^{P C}(t)$, and $P_{\text {load }}^{P H}(t)$. Moreover, the first four $C_{\text {load }}^{P C}(t), C_{\text {load }}^{G C}(t)$, $H_{\text {load }}^{P H}(t)$, and $H_{\text {load }}^{G H}(t)$ are actually the final state of the convertible load, while the last four $G_{\text {load }}^{G C}(t)$, $G_{\text {load }}^{G H}(t), P_{\text {load }}^{P C}(t)$, and $P_{\text {load }}^{P H}(t)$ are actually the initial state of the convertible load.

The total amount of energy of composite load in the final energy form (cooling or heat) can thus be expressed by

$$
\left\{\begin{array}{l}
p_{\text {load }}^{P C} P_{\text {load }}^{P C}(t)+C_{\text {load }}^{P C}(t)=L_{\text {load }}^{P C}(t) \\
g_{\text {load }}^{G C} G_{\text {load }}^{G C}(t)+C_{\text {load }}^{G C}(t)=L_{\text {lood }}^{G C}(t) \\
p_{\text {load }}^{P H} P_{\text {load }}^{P H}(t)+H_{\text {load }}^{P H}(t)=L_{\text {load }}^{P H}(t) \\
g_{\text {load }}^{G H} G_{\text {load }}^{G H}(t)+H_{\text {load }}^{G H}(t)=L_{\text {load }}^{G H}(t)
\end{array},\right.
$$

where $p_{\text {load }}^{P C}$ represents the energy efficiency ratio of convertible cooling-oriented power load; $L_{\text {load }}^{P C}(t)$ represents the composite power and cooling load; $g$ load represents the energy efficiency ratio of convertible cooling-oriented gas load; $L_{\text {load }}^{G C}(t)$ represents the composite power and gas load; $p_{\text {load }}^{P H}$ represents the energy efficiency ratio of convertible heat-oriented power load; $L_{\text {load }}^{P H}(t)$ represents the composite power and heat load; $g_{\text {load }}^{G H}$ represents the energy efficiency ratio of convertible heat-oriented gas load; and $L_{\text {load }}^{G H}(t)$ represents the composite gas and heat load. 


\subsubsection{Energy Balance of Conversion Systems}

As can be seen from Figure 2, the conversion systems comprise the CHP plant, gas turbine, gas boiler, electric heater and electric furnace. In this section, the input and output energy balance of respective conversion system is presented.

The CHP plant is the use of natural gas to generate electricity and useful heat simultaneously. The relation between input gas power and output electricity or heat power of the back pressure CHP plant is

$$
\begin{aligned}
& P_{C H P}(t)=p_{C H P} G_{C H P}(t) \\
& Q_{C H P}(t)=q_{Q P} P_{C H P}(t),
\end{aligned}
$$

where $p_{C H P}$ represents the power generation efficiency of the CHP plant; $q_{Q P}$ represents the ratio of electricity-to-heat; $G_{C H P}$ represents the input gas power of the CHP plant; and $Q_{C H P}$ represents the surplus heat, which is transformed to cooling and heat energy through the absorption refrigerator and heat exchanger, respectively.

$$
\begin{gathered}
C_{A R}(t)=\eta_{A R}\left(1-\gamma_{H C}\right) Q_{C H P}(t), \\
H_{H E}(t)=\eta_{H E} \gamma_{H C} Q_{C H P}(t) .
\end{gathered}
$$

where $\eta_{A R}$ and $\eta_{H E}$ represent the energy efficiency ratio of the absorption refrigerator and heat exchanger; $\gamma_{H C}$ represents the proportion ratio.

The gas turbine is used to transform gas energy into electricity energy

$$
P_{G T}(t)=\eta_{G T} G_{G T}(t),
$$

where $\eta_{G T}$ represents the energy efficiency ratio of the gas turbine.

The gas boiler is used to transform gas energy into heat energy

$$
H_{G B}(t)=\eta_{G B} G_{G B}(t),
$$

where $\eta_{G B}$ represents the energy efficiency ratio of the gas boiler.

The electric refrigerator is used to transform electricity energy into cooling energy

$$
C_{E R}(t)=\eta_{E R} P_{E R}(t)
$$

where $\eta_{E R}$ represents the energy efficiency ratio of the the electric refrigerator.

The electric heater is used to transform electricity energy into heat energy

$$
H_{E H}(t)=\eta_{E H} P_{E H}(t),
$$

where $\eta_{E H}$ represents the energy efficiency ratio of the electric heater.

\subsubsection{Energy Storage Systems}

Operating constraints of the energy storage system mainly comprise the storage state and some output constraints no matter it is the electricity, heat or cooling storage system. Take the electricity energy storage system as an example, the typical operating model can be written as 


$$
\left\{\begin{array}{l}
S_{P S}(t)=\left(1-\eta_{P S}\right) S_{P S}(t-1)+\eta_{P S}^{S} P_{P S}^{S}(t)-P_{P S}^{R}(t) / \eta_{P S}^{R} \\
S_{P S}^{\min } \leq S_{P S}(t) \leq S_{P S}^{\max } \\
S_{P S}\left(t_{1}\right)=S_{P S}\left(t_{e n d}\right) \\
U_{P S}^{S}(t) P_{P S}^{\min } \leq P_{P S}^{S}(t) \leq U_{P S}^{S}(t) P_{P S}^{\max } \\
U_{P S}^{R}(t) P_{P S}^{\min } \leq P_{P S}^{R}(t) \leq U_{P S}^{R}(t) P_{P S}^{\max } \\
U_{P S}^{R}(t)+U_{P S}^{S}(t) \leq 1 \\
U_{P S}^{R}(t), U_{P S}^{S}(t) \in(0,1)
\end{array}\right.
$$

where $S_{P S}(t)$ represents the remaining power in the electricity energy storage system; $\eta_{P S}$ represents the attrition rate during the charge/discharge process; $\eta_{P S}^{S}$ represents the charge efficiency; $\eta_{P S}^{R}$ represents the discharge efficiency; $U_{P S}^{S}(t)$ represents the on/off charge state; $U_{P S}^{R}(t)$ represents the on/off discharge state; $S_{P S}^{\min }$ and $S_{P S}^{\max }$ represents the capacity limit; $S_{P S}\left(t_{1}\right)$ represents the initial power in the beginning of one cycle of operation; and $S_{P S}\left(t_{\text {end }}\right)$ represents the final power in the end of one cycle of operation. When considering the periodicity of the operation of ESS (energy storage system), the final power of the previous cycle should be equal to the initial power of the next cycle; hence, $S_{P S}\left(t_{\text {end }}\right)=S_{P S}\left(t_{1}\right)$ should be satisfied.

\subsubsection{Other Constraints}

In addition to constraints characterizing energy supply and demand balance, input and output energy relation of conversion systems, other mentionable operating constraints are those that describe the output limit of specific components in MES.

Firstly, the convertible load in each energy network has its lower/upper limit:

$$
\left\{\begin{array}{l}
\underline{P}_{\text {load }}^{\mathrm{PC}} \leq P_{\text {load }}^{\mathrm{PC}}(t) \leq \bar{P}_{\text {load }}^{\mathrm{PC}} \\
\underline{C}_{\text {load }}^{\mathrm{PC}} \leq C_{\text {load }}^{\mathrm{PC}}(t) \leq \bar{C}_{\text {load }}^{\mathrm{PC}} \\
\underline{P}_{\text {load }}^{\mathrm{PH}} \leq P_{\text {load }}^{\mathrm{PH}}(t) \leq \bar{P}_{\text {load }}^{\mathrm{PH}} \\
\underline{H}_{\text {load }}^{\mathrm{PH}} \leq H_{\text {load }}^{\mathrm{PH}}(t) \leq \bar{H}_{\text {load }}^{\mathrm{PH}} \\
\underline{G}_{\text {load }}^{\mathrm{GC}} \leq G_{\text {load }}^{\mathrm{GC}} \leq \bar{G}_{\text {load }}^{\mathrm{GC}} \\
\underline{C}_{\text {load }}^{\mathrm{GC}} \leq C_{\text {load }}^{\mathrm{GC}}(t) \leq \bar{C}_{\text {load }}^{\mathrm{GC}} \\
\underline{G}_{\text {load }}^{\mathrm{GH}} \leq G_{\text {load }}^{\mathrm{GH}} \leq \overline{\mathrm{G}}_{\text {load }}^{\mathrm{PH}} \\
\underline{H}_{\text {load }}^{\mathrm{GH}} \leq H_{\text {load }}^{\mathrm{GH}}(t) \leq \bar{H}_{\text {load }}^{\mathrm{GH}}
\end{array} .\right.
$$

Secondly, the output of conversion system has its lower/upper limit:

$$
\left\{\begin{array}{l}
\underline{P}_{\mathrm{CHP}} \leq P_{\mathrm{CHP}}(t) \leq \bar{P}_{\mathrm{CHP}} \\
\underline{P}_{\mathrm{GT}} \leq P_{\mathrm{GT}}(t) \leq \bar{P}_{\mathrm{GT}} \\
\underline{H}_{\mathrm{GB}} \leq H_{\mathrm{GB}}(t) \leq \bar{H}_{\mathrm{GB}} \\
\underline{C}_{\mathrm{ER}} \leq C_{\mathrm{ER}}(t) \leq \bar{C}_{\mathrm{ER}} \\
\underline{H}_{\mathrm{EH}} \leq H_{\mathrm{EH}}(t) \leq \bar{H}_{\mathrm{EH}}
\end{array} .\right.
$$

Thirdly, the purchase amount of electricity $P_{e x t}(t)$ and gas $G_{e x t}(t)$ cannot be unlimited; it is assumed that they cannot surpass the allowable maximum.

$$
\left\{\begin{array}{l}
0 \leq P_{\text {ext }}(t) \leq P_{\text {ext }}^{\max } \\
0 \leq G_{\text {ext }}(t) \leq G_{\text {ext }}^{\max }
\end{array} .\right.
$$

Based on (26) it can be learned that the minimal purchase amount from external electricity or gas network is nonnegative. Particularly with respect to gas purchase, since gas is the only crude source which is used as the primitive input energy of all conversion systems and multi-generation plants, it cannot be less than zero. Otherwise, it means MES can autonomously inject gas toward 
external network out of nothing, which is against the law of conservation of energy. On the other hand, the electricity purchased takes the role of auxiliary, which can act as supplementary energy provider in due time. Because of the existence of gas load, electricity purchased cannot single-handedly solve the energy supply problem. Nevertheless, the energy supplier for heat and cooling load could be electricity purchased.

The model (7)-(26) belongs to mixed integer linear programming (MILP) and is solved by commercial optimization software package CPLEX under general algebraic modelling system (GAMS).

\section{Case Study}

In this section, MES in Figure 2 is used for numerical analyses. Specifically, the intrinsic relation between load replaceability (as is quantified by (4) and (6)) and optimal scheduling results is studied, and thus giving a priori knowledge of improving economic scheduling performance by reformulating the composite load.

\subsection{Simulation Settings}

Parameters of main system components are given in Table 1.

Table 1. Parameters and corresponding values of MES.

\begin{tabular}{lc}
\hline Parameter & Value \\
\hline maximum allowable electricity procurement $P_{e x t}^{\max }$ & $12,000 \mathrm{~kW}$ \\
maximum allowable gas procurement $G_{e x t}^{\max }$ & $60,000 \mathrm{~kW}$ \\
maximum output of electric heater $\bar{H}_{E H}$ & $2000 \mathrm{~kW}$ \\
maximum output of electric refrigerator $\bar{C}_{E R}$ & $2000 \mathrm{~kW}$ \\
maximum output electricity of $C H P$ plant $\bar{P}_{C H P}$ & $8000 \mathrm{~kW}$ \\
maximum output of heat exchanger $\bar{H}_{H E}$ & $4000 \mathrm{~kW}$ \\
maximum output of absorption refrigerator $\bar{C}_{A R}$ & $6000 \mathrm{~kW}$ \\
maximum output of gas boiler $\bar{H}_{G B}$ & $2000 \mathrm{~kW}$ \\
maximum output of gas turbine $\bar{P}_{G T}$ & $8000 \mathrm{~kW}$ \\
power generation efficiency of CHP plant $p_{C H P}$ & 0.3 \\
electricity-to-heat ratio of CHP plant $\eta_{Q P}$ & $2 / 3$ \\
energy efficiency ratio of heat exchanger $\eta_{H E}$ & 0.9 \\
energy efficiency ratio of absorption refrigerator $\eta_{A R}$ & 0.9 \\
energy efficiency ratio of electric heater $\eta_{E H}$ & 0.95 \\
energy generation proportion ratio $\gamma_{H C}$ & 0.6 \\
energy efficiency ratio of electric refrigerator $\eta_{E R}$ & 3.5 \\
energy efficiency ratio of gas boiler $\eta_{G B}$ & 0.9 \\
maximum charge/discharge energy of electricity ESS $P_{P S}^{\max }$ & $2000 \mathrm{~kW}$ \\
maximum charge/discharge energy of heat ESS $H_{H S}^{\max }$ & $1000 \mathrm{~kW}$ \\
maximum charge/discharge energy of cooling ESS $P_{P S}^{\max }$ & $2000 \mathrm{~kW}$ \\
maximum remaining energy of electricity ESS $S_{P S}^{\max }$ & $8000 \mathrm{kWh}$ \\
maximum remaining energy of heat ESS $S_{H S}^{\max }$ & $4000 \mathrm{kWh}$ \\
maximum remaining energy of cooling ESS $S_{C S}^{\max }$ & $8000 \mathrm{kWh}$ \\
attrition rate of electricity ESS $\eta_{P S}$ & $0.2 \%$ \\
attrition rate of heat ESS $\eta_{H S}$ & $0.3 \%$ \\
attrition rate of cooling ESS $\eta_{C S}$ operating cost of electricity ESS $r_{P S}$ & $0.2 \%$ \\
operating cost of heat ESS $r_{H S}$ & $0.32 \$ / \mathrm{kWh}$ \\
operating cost of cooling ESS $r_{C S}$ & $0.25 \$ / \mathrm{kWh}$ \\
\hline & $0.2 \$ / \mathrm{kWh}$ \\
\hline
\end{tabular}

The load status described by loading rate at every scheduling interval is shown in Figure 3. 


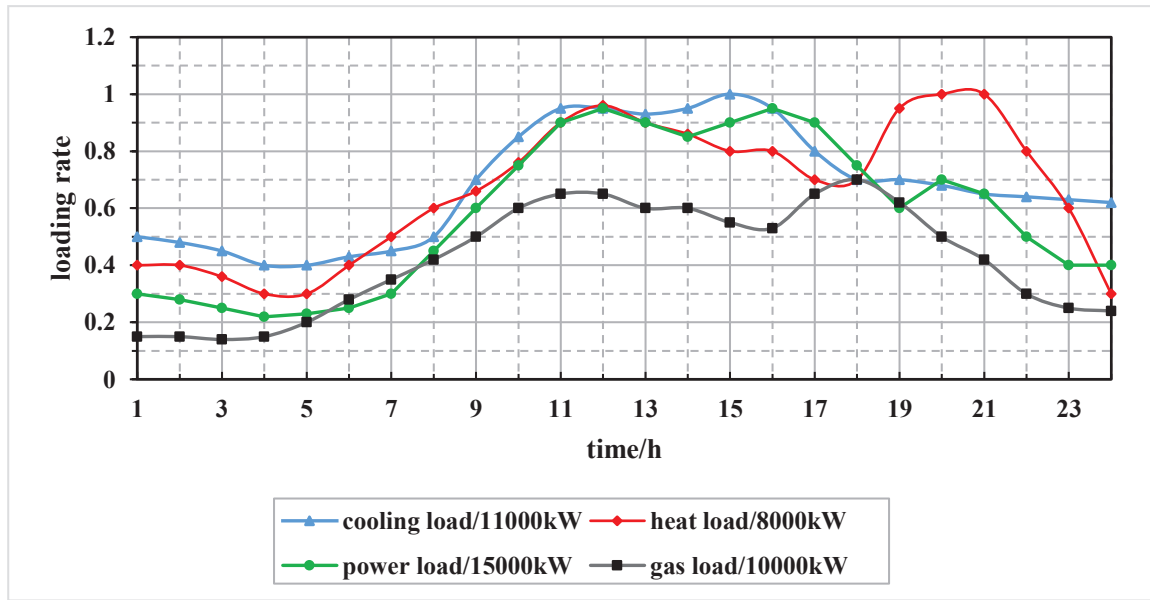

Figure 3. Hourly load status of gas, power, and heat and cooling load of MES.

The rated power of cooling, heat, and power and gas load is $11,000 \mathrm{~kW}, 8000 \mathrm{~kW}, 15,000 \mathrm{~kW}$, and $10,000 \mathrm{~kW}$, respectively. The day-ahead price information from the electricity and gas market is given in Table 2.

Table 2. Time-of-Use price of gas and electricity in a day.

\begin{tabular}{lcll}
\hline Periods & $r_{\text {gas }}$ & Periods & $\boldsymbol{r}_{\text {ele }}$ \\
\hline 00:00-07:00 & 2.7 & $00: 00-08: 00$ & 0.35 \\
07:00-12:00 & 3.3 & $08: 00-12: 00$ & 1.65 \\
12:00-16:00 & 3.0 & $12: 00-17: 00$ & 0.95 \\
16:00-20:00 & 3.3 & $17: 00-21: 00$ & 1.65 \\
20:00-24:00 & 3.0 & 21:00-24:00 & 0.95 \\
\hline
\end{tabular}

\subsection{Simulation Results and Discussions}

After presenting the basic simulation settings, optimal scheduling and its relation with load replaceability is studied by calculating the scheduling model in (7)-(9) in Section 3 and LRI in (3)-(6) in Section 2.2. As previously addressed in Section 2.2, there exist two ways of describing the load replacement capability of MES; therefore, by special setting of composite load in (14), we change the values of LRI both in (4) and (6), and analyze the resulting influence upon optimal scheduling results through a sensitivity analysis tests. Specifically, the following 2 scenarios are considered.

\subsubsection{Scenario 1}

It is supposed that the composite load is of electricity-cooling and electricity-heat types. As for composite electricity-cooling load, the rated capacity of alternative electricity load is fixed to $2000 \mathrm{~kW}$, while the capacity of alternative cooling load is increased from $600 \mathrm{~kW}$ to $6000 \mathrm{~kW}$ at the step size of $600 \mathrm{~kW}$. Similarly, the rated capacity of alternative electricity load is fixed to $3750 \mathrm{~kW}$ in composite electricity-heat load, while the the capacity of alternative heat load is increased from $300 \mathrm{~kW}$ to $3000 \mathrm{~kW}$ at the step size of $300 \mathrm{~kW}$. Consequently, 10 LRIs can be calculated based on (4) and (6), and the results are shown in Figure 4. 


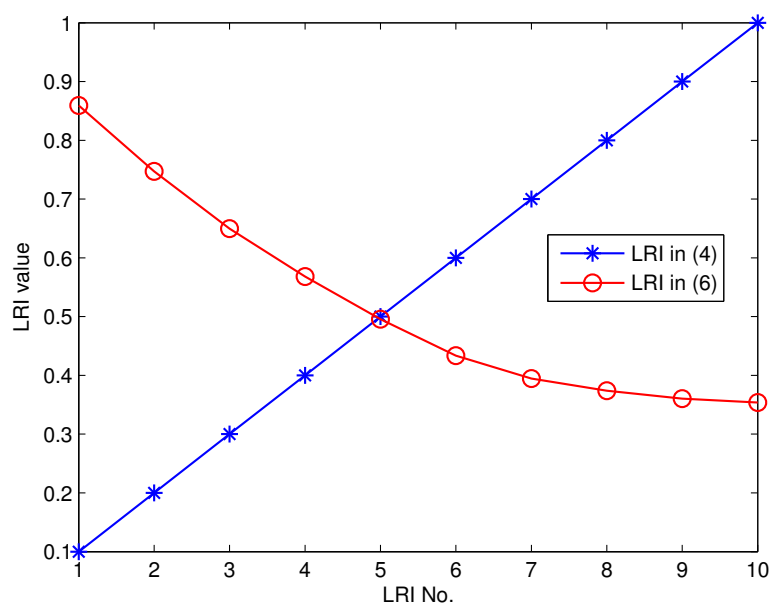

Figure 4. load replaceability index (LRI) with and without optimal scheduling in Scenario 1.

As can be seen from the blue curve in Figure 4, with the increase of alternative cooling and heat load, the remaining alternative load reserve is elevated from $900 \mathrm{~kW}$ to $9000 \mathrm{~kW}$, thus enhancing LRI from 0.1 to 1 . Meanwhile, the red curve shows that the proportion of energy converted by intermediate loads in the actual scheduling drops as the rated capacity of alternative heat (cooling) load increases, which means the operator chooses to obtain heat or cooling energy through redundant conversion paths. Take the electricity-cooling load as an example, the redundant conversion path is shown in dashed black line in Figure 5.

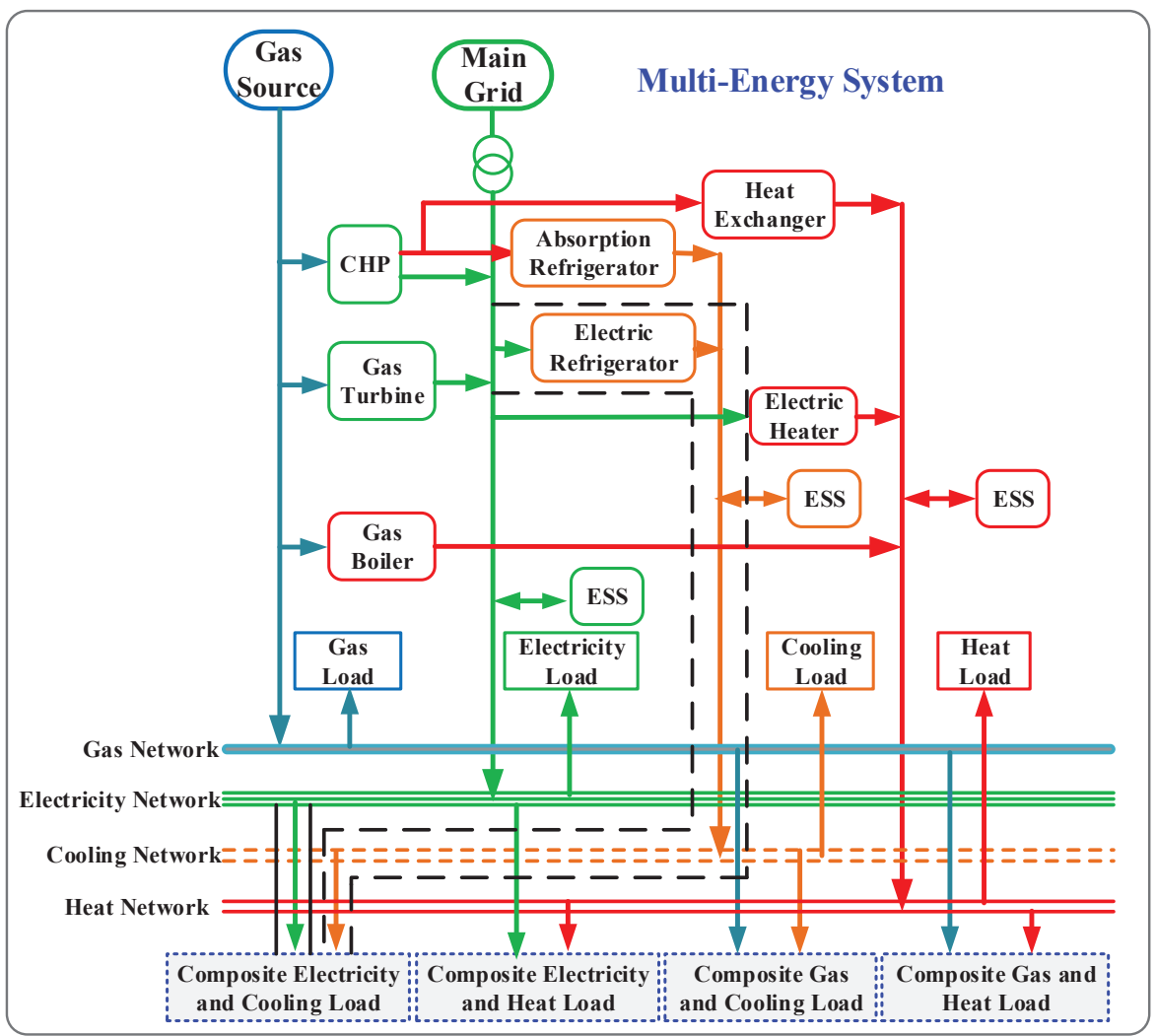

Figure 5. Redundant conversion path of electricity-cooling load in Scenario 1. 
Due to the fact that energy efficiency ratio of electric refrigerator is much higher than that of alternative electricity load in the composite electricity and cooling load. The operator chooses redundant path such that more cooling energy can be harvested with equal amount of electricity energy. Similar conclusions can be made in respect to composite electricity and heat load. Therefore, the proportion of energy converted by intermediate electricity load in the composite load is decreased with the increase of transmission capacity of redundant paths, which is equivalent to the drop of LRI (from 0.86 to 0.35 ). Furthermore, the relation between LRI and optimal scheduling results in Scenario 1 is shown in Figures 6 and 7.

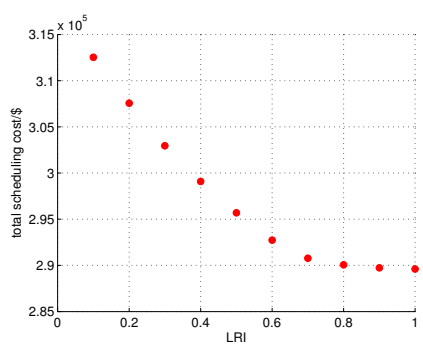

(a)

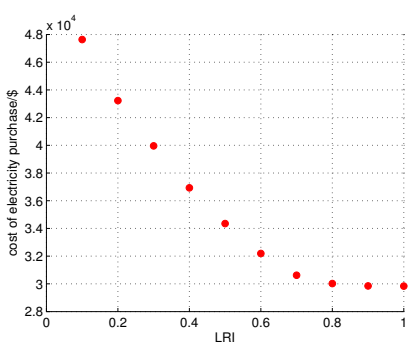

(b)

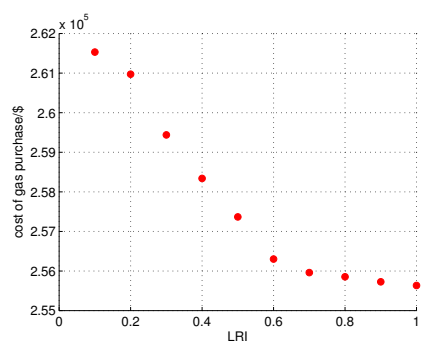

(c)

Figure 6. Relation between offline potential-based LRI and optimal scheduling results in Scenario 1. (a) The relation between LRI and optimal energy cost. (b) The relation between LRI and optimal cost of electricity purchase. (c) The relation between LRI and optimal cost of gas purchase.

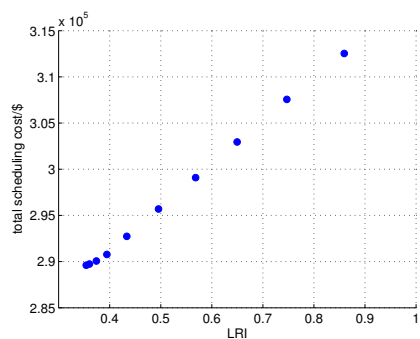

(a)

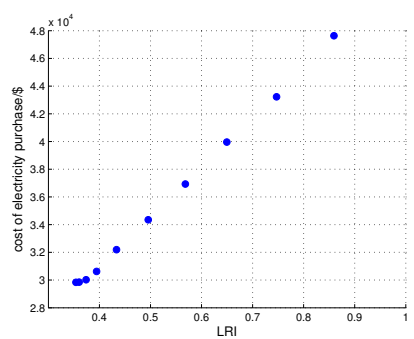

(b)

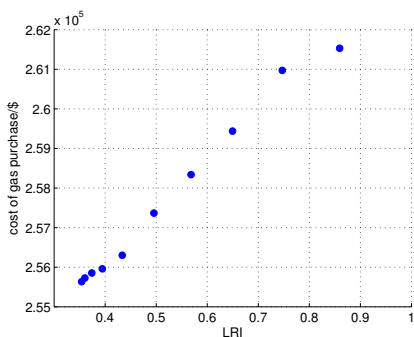

(c)

Figure 7. Relation between online scheduling-based LRI and optimal scheduling results in Scenario 1. (a) The relation between LRI and optimal energy cost. (b) The relation between LRI and optimal cost of electricity purchase. (c) The relation between LRI and optimal cost of gas purchase.

As can be seen from Figure 6, the cost including cost of gas and electricity purchase decreases with the increase of offline potential-based LRI. Contrarily, there exists a positive correlation between energy cost and online scheduling-based LRI. It verifies that the optimization space can be enhanced by elevating the capacity of alternative load, thus enabling the decrease of minimal scheduling costs.

\subsubsection{Scenario 2}

It is supposed that the composite load is of gas-cooling and gas-heat types. As for composite gas-cooling load, the rated capacity of alternative gas load is fixed to $5000 \mathrm{~kW}$, while the capacity of alternative cooling load is increased from $600 \mathrm{~kW}$ to $6000 \mathrm{~kW}$ at the step size of $600 \mathrm{~kW}$. Similarly, the rated capacity of alternative gas load is fixed to $6000 \mathrm{~kW}$ in composite gas-heat load, while the the capacity of alternative heat load is increased from $300 \mathrm{~kW}$ to $3000 \mathrm{~kW}$ at the step size of $300 \mathrm{~kW}$. Consequently, 10 LRIs can be calculated based on (4) and (6), and the results are shown in Figure 8. 


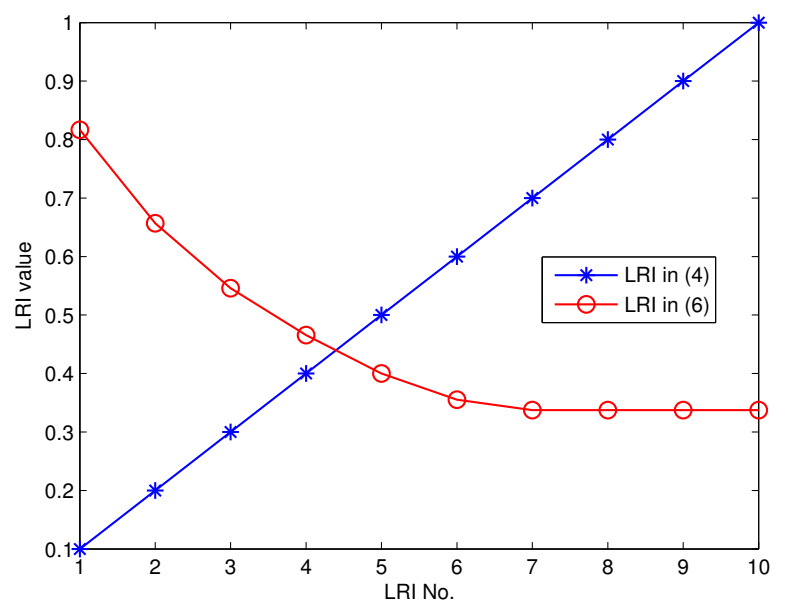

Figure 8. LRI with and without optimal scheduling in Scenario 2.

The relation between LRI and optimal scheduling results in Scenario 2 is shown in Figures 9 and 10.

Similar to Scenario 1, it can be learned that the optimal energy cost can be decreased by elevating the offline potential based LRI, which quantifies the maximum alternative load capacity of the system. In addition, it can be found that the optimal cost does not decrease when LRI reaches the critical state. It means that there is no unrestricted expansion of optimization space by single-handedly elevating alternative load capacity, which could improve the expectancy of optimum under the joint force of other factors such as system configuration and market price signals.

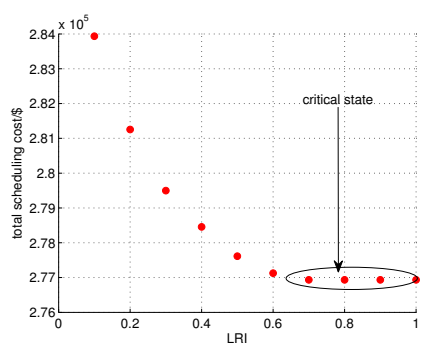

(a)

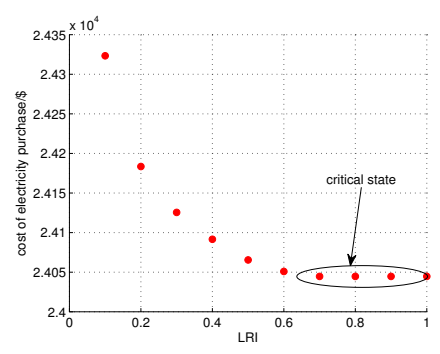

(b)

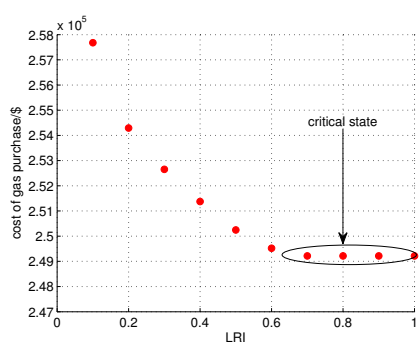

(c)

Figure 9. Relation between offline potential-based LRI and optimal scheduling results in Scenario 2. (a) The relation between LRI and optimal energy cost. (b) The relation between LRI and optimal cost of electricity purchase. (c) The relation between LRI and optimal cost of gas purchase.

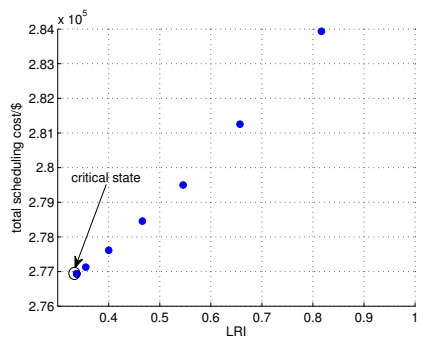

(a)

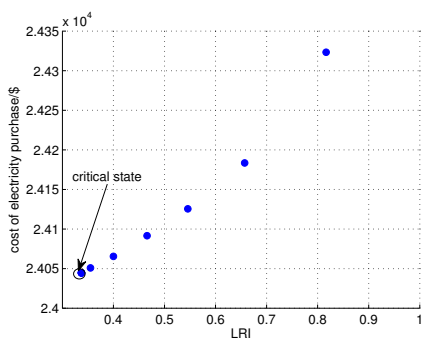

(b)

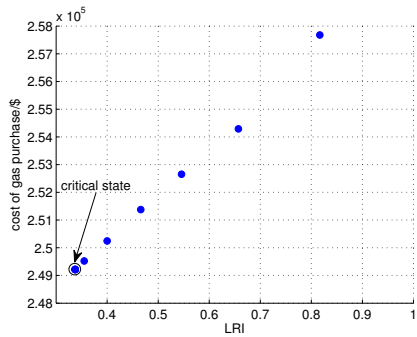

(c)

Figure 10. Relation between online scheduling-based LRI and optimal scheduling results in Scenario 2. (a) The relation between LRI and optimal energy cost. (b) The relation between LRI and optimal cost of electricity purchase. (c) The relation between LRI and optimal cost of gas purchase.

\section{Conclusions}

In this paper, optimal economic scheduling of multi-energy systems considering load replaceability is presented. Two types of LRI reflecting the offline potential and online scheduling 
performance are designed, and the relation between LRI and optimal scheduling results is analyzed. Through numerical analysis, it can be found that optimal scheduling performance can be improved by increasing the alternative load capacity (offline potential-based LRI). And this improvement is not unrestricted and could only maintain by changing load replaceability in a limited range, after which the optimum reaches the saturation phase.

Author Contributions: T.Z. and Z.D. conceived and designed the experiments; J.Y. performed the experiment; T.Z. wrote the paper; Y.Y. and J.C. reviewed the paper.

Funding: This work was supported by the National Key Research and Development Program of China (2018YFB0905000) and the project of 'Study and application of multi-energy micro-grid source-network-load-storage coordinated control system' of NARI Group Corporation (State Grid Electric Power Research Institute).

Conflicts of Interest: The authors declare no conflict of interest.

\section{References}

1. Vasebi, A.; Fesanghary, M.; Bathaee, S. Combined heat and power economic dispatch by harmony search algorithm. Int. J. Electr. Power Energy Syst. 2007, 29, 713-719. [CrossRef]

2. Vögelin, P.; Koch, B.; Georges, G.; Boulouchos, K. Heuristic approach for the economic optimisation of combined heat and power (CHP) plants: Operating strategy, heat storage and power. Energy 2017, 121, 66-77. [CrossRef]

3. Wu, C.; Jiang, P.; Sun, Y.; Zhang, C.; Gu, W. Economic dispatch with chp and wind power using probabilistic sequence theory and hybrid heuristic algorithm. J. Renew. Sustain. Energy 2017, 9, 013303. [CrossRef]

4. Li, Z.; Wu, W.; Shahidehpour, M.; Wang, J.; Zhang, B. Combined heat and power dispatch considering pipeline energy storage of district heating network. IEEE Trans. Sustain. Energy 2015, 7, 12-22. [CrossRef]

5. Hashemi, R. A developed offline model for optimal operation of combined heating and cooling and power systems. IEEE Trans. Energy Convers. 2009, 24, 222-229. [CrossRef]

6. Facci, A.L.; Andreassi, L.; Ubertini, S. Optimization of CHCP (combined heat power and cooling) systems operation strategy using dynamic programming. Energy 2014, 66, 387-400. [CrossRef]

7. Li, M.; Mu, H.; Li, N. Optimal design and operation strategy for integrated evaluation of CCHP (combined cooling heating and power) system. Energy 2016, 99, 202-220. [CrossRef]

8. Tan, Z.; Guo, H.; Lin, H.; Tan, Q.; Yang, S.; Gejirifu, D.; Ju, L.; Song, X. Robust scheduling optimization model for multi-energy interdependent system based on energy storage technology and ground-source heat pump. Processes 2019, 7, 27. [CrossRef]

9. Wang, M.; Wang, J.; Zhao, P.; Dai, Y. Multi-objective optimization of a combined cooling, heating and power system driven by solar energy. Energy Convers. Manag. 2015, 89, 289-297. [CrossRef]

10. Motevasel, M.; Seifi, A.R.; Niknam, T. Multi-objective energy management of CHP (combined heat and power)-based micro-grid. Energy 2013, 51, 123-136. [CrossRef]

11. Li, K.; Yan, H.; He, G.; Zhu, C.; Liu, K.; Liu, Y. Seasonal Operation Strategy Optimization for Integrated Energy Systems with Considering System Cooling Loads Independently. Processes 2018, 6, 202. [CrossRef]

12. Zhang, X.; Shahidehpour, M.; Alabdulwahab, A.; Abusorrah, A. Optimal expansion planning of energy hub with multiple energy infrastructures. IEEE Trans. Smart Grid 2015, 6, 2302-2311. [CrossRef]

13. Parisio, A.; Del Vecchio, C.; Vaccaro, A. A robust optimization approach to energy hub management. Int. J. Electr. Power Energy Syst. 2012, 42, 98-104. [CrossRef]

14. Vahid-Pakdel, M.; Nojavan, S.; Mohammadi-Ivatloo, B.; Zare, K. Stochastic optimization of energy hub operation with consideration of thermal energy market and demand response. Energy Convers. Manag. 2017, 145, 117-128. [CrossRef]

15. Huang, Y.; Zhang, W.; Yang, K.; Hou, W.; Huang, Y. An optimal scheduling method for multi-energy hub systems using game theory. Energies 2019, 12, 2270. [CrossRef]

16. Lin, Y.; Chen, B.; Wang, J.; Bie, Z. A combined repair crew dispatch problem for resilient electric and natural gas system considering reconfiguration and DG islanding. IEEE Trans. Power Syst. 2019, 34, 2755-2767. [CrossRef] 
17. Liu, Z.; Yang, P.; Xu, Z. Capacity allocation of integrated energy system considering typical day economic operation. Electr. Power Constr. 2017, 38, 51-59.

18. Zhao, F.; Sun, B.; Zhang, C. Cooling, heating and electrical load forecasting method for CCHP system based on multivariate phase space reconstruction and Kalman filter. Proc. CSEE 2016, 36, 399-406.

19. Chen, F.; Xu, J.; Wang, C. Research on building cooling and heating load prediction model on user's side in energy internet system. Proc. CSEE 2015, 35, 3678-3684.

20. Shi, J.; Tan, T.; Guo, J. Multi-task learning based on deep architecture for various types of load forecasting in regional energy system integration. Power Syst. Technol. 2018, 42, 698-706.

21. Sheikhi, A.; Rayati, M.; Bahrami, S. Integrated demand side management game in smart energy hubs. IEEE Trans. Smart Grid 2015, 6, 675-683. [CrossRef]

22. Bahrami, S.; Sheikhi, A. From demand response in smart grid toward integrated demand response in smart energy hub. IEEE Trans. Smart Grid 2016, 7, 650-658. [CrossRef]

(c) 2019 by the authors. Licensee MDPI, Basel, Switzerland. This article is an open access article distributed under the terms and conditions of the Creative Commons Attribution (CC BY) license (http:/ / creativecommons.org/licenses/by/4.0/). 